\title{
Comparison of hydrogen storage properties of pure Mg and milled pure Mg
}

\author{
MYOUNG YOUP SONG ${ }^{\mathrm{a}, *}$, YOUNG JUN KWAK ${ }^{\mathrm{b}}$, SEONG HO LEE ${ }^{\mathrm{b}}$ and \\ HYE RYOUNG PARK ${ }^{\mathrm{c}}$ \\ ${ }^{a}$ Division of Advanced Materials Engineering, Hydrogen \& Fuel Cell Research Centre, Engineering Research \\ Institute, Chonbuk National University, 567 Baekje-daero Deokjin-gu Jeonju 561-756, South Korea \\ ${ }^{\mathrm{b}}$ Department of Materials Engineering, Graduate School, Chonbuk National University, 567 Baekje-daero \\ Deokjin-gu Jeonju 561-756, South Korea \\ ${ }^{\mathrm{c}}$ School of Applied Chemical Engineering, Chonnam National University, 77 Yongbong-ro Buk-gu Gwangju \\ 500-757, South Korea
}

MS received 12 March 2013; revised 27 May 2013

\begin{abstract}
Hydrogen storage properties of pure $\mathrm{Mg}$ were studied at $593 \mathrm{~K}$ under 12 bar $\mathrm{H}_{2}$. In order to increase the hydriding and dehydriding rates, pure $\mathrm{Mg}$ was ground under hydrogen atmosphere (reactive mechanical grinding, RMG) and its hydrogen storage properties were subsequently investigated. Pure Mg absorbed hydrogen very slowly. At the number of cycles $(n)$ of 1 , pure $\mathrm{Mg}$ absorbed $0.05 \mathrm{wt} \% \mathrm{H}$ for $5 \mathrm{~min}$, $0.08 \mathrm{wt} \% \mathrm{H}$ for $10 \mathrm{~min}$ and $0.29 \mathrm{wt} \% \mathrm{H}$ for $60 \mathrm{~min}$ at $593 \mathrm{~K}$ under $12 \mathrm{bar} \mathrm{H}_{2}$. Activation was completed at the fifth cycle. At $n=6$, pure Mg absorbed $1.76 \mathrm{wt} \% \mathrm{H}$ for $5 \mathrm{~min}, 2.17 \mathrm{wt} \% \mathrm{H}$ for $10 \mathrm{~min}$ and $3.40 \mathrm{wt} \% \mathrm{H}$ for $60 \mathrm{~min}$. The activation of pure Mg after RMG was completed at the sixth cycle. At $n=7$, pure Mg after RMG absorbed $2.57 \mathrm{wt} \% \mathrm{H}$ for $5 \mathrm{~min}, 3.21 \mathrm{wt} \% \mathrm{H}$ for $10 \mathrm{~min}$ and $4.15 \mathrm{wt} \% \mathrm{H}$ for $60 \mathrm{~min}$.
\end{abstract}

Keywords. Hydrogen absorbing materials; pure magnesium; mechanical alloying/milling; microstructure; $\mathrm{X}$-ray diffraction.

\section{Introduction}

Magnesium has many advantages as a hydrogen storage material in terms of hydrogen storage capacity, cost and reserves in the earth's crust. However, the reaction rate of Mg with $\mathrm{H}_{2}$ is very low (Hong et al 2013a). Extensive research has been conducted to improve the hydriding and dehydriding rates of magnesium by alloying with certain magnesium metals (Hong et al 2013b; Kwak et al 2013; Song et al 2013a,b,c,d,), including Cu (Reilly and Wiswall 1967), Ni (Reilly and Wiswall 1968; Akiba et al 1982), In (Mintz et al 1978), Sn (Zhong et al 2011), V (Pei et al 2012) and Ni and Y (Li et al 2007), by synthesizing compounds such as $\mathrm{CeMg}_{12}$ (Boulet and Gerard 1983) and $\mathrm{Mg}_{76} \mathrm{Ti}_{12} \mathrm{Fe}_{12-x} \mathrm{Ni}_{x} \quad(x=4,8)$ (Lucaci et al 2009), and by fabricating composites such as $\mathrm{Mg}$ $20 \mathrm{wt} \% \mathrm{Fe}_{23} \mathrm{Y}_{8}$ (Li et al 2006). Aminorroaya et al (2011) added $\mathrm{Nb}$ and multi-walled carbon nanotubes to $\mathrm{Mg}-\mathrm{Ni}$ alloys and Cho et al (2011) added transition metals to cast $\mathrm{Mg}-\mathrm{Ni}$ alloys to improve the reaction rate of $\mathrm{Mg}$ with $\mathrm{H}_{2}$. Milanese et al (2010) mixed $\mathrm{Ni}$ and $\mathrm{Cu}$ with $\mathrm{Mg}$, Tanguy et al (1976) mixed metal additives with magnesium and Eisenberg et al (1980) plated nickel on the

*Author for correspondence (songmy@jbnu.ac.kr) surface of magnesium to improve the hydridingdehydriding kinetics of $\mathrm{MgH}_{2}$.

In this work, hydrogen storage properties of pure $\mathrm{Mg}$ were studied. In order to increase the hydriding and dehydriding rates, pure Mg was ground under hydrogen atmosphere (reactive mechanical grinding, RMG) and its hydrogen storage properties were investigated. The hydrogen storage properties of pure $\mathrm{Mg}$ and pure $\mathrm{Mg}$ after RMG were then compared.

\section{Experimental}

Pure Mg powder $(-100+200$ mesh, 99.6\%, Alfa Aesar) or pure $\mathrm{MgH}_{2}$ (hydrogen storage grade, Aldrich) was used as a starting material.

Reactive mechanical grinding was performed in a planetary ball mill (Planetary Mono Mill; Pulverisette 6, Fritsch). Pure $\mathrm{Mg}$ or pure $\mathrm{MgH}_{2}$ (total weight $=8 \mathrm{~g}$ ) was mixed in a hermetically sealed stainless steel container with 105 hardened steel balls (total weight $=360 \mathrm{~g}$ ); the sample to ball weight ratio was 1:45. All sample handling was performed in a glove box under $\mathrm{Ar}$ in order to prevent oxidation. The disc revolution speed was $250 \mathrm{rpm}$. The mill container (volume, $250 \mathrm{~mL}$ ) was then filled with high purity hydrogen gas ( $12 \mathrm{bar})$. The 
reactive mechanical grinding was performed for $6 \mathrm{~h}$ by repeating $15 \mathrm{~min}$ milling and $5 \mathrm{~min}$ rest. The mill container was refilled with hydrogen every $2 \mathrm{~h}$.

The quantity of absorbed or desorbed hydrogen was measured as a function of time by a volumetric method using a Sivert's type hydriding and dehydriding apparatus, which has been described in previous research (Song et al 2010). The sample weight used for this measurement was $0.5 \mathrm{~g}$. The samples after reactive mechanical grinding and after hydriding-dehydriding cycling were characterized by X-ray diffraction (XRD) with CuK $\alpha$ radiation using a Rigaku D/MAX 2500 powder diffractometer. The microstructures of the powders were examined with a JSM-6400 scanning electron microscope (SEM) operated at $20 \mathrm{kV}$.

\section{Results and discussion}

The weight percentage of absorbed hydrogen, $H_{\mathrm{a}}$, is expressed with respect to sample weight. Figure 1 shows variation of $H_{\mathrm{a}}$ vs $t$ curve with the number of cycles, $n$, for pure $\mathrm{Mg}$ at $593 \mathrm{~K}$ under 12 bar $\mathrm{H}_{2}$. The pure $\mathrm{Mg}$ sample absorbs hydrogen very slowly. At $n=1$, pure Mg absorbs $0.05 \mathrm{wt} \% \mathrm{H}$ for $5 \mathrm{~min}, 0.08 \mathrm{wt} \% \mathrm{H}$ for $10 \mathrm{~min}$, $0.17 \mathrm{wt} \% \mathrm{H}$ for $30 \mathrm{~min}$ and $0.29 \mathrm{wt} \% \mathrm{H}$ for $60 \mathrm{~min}$. The hydriding rate increases as the number of cycles increases from $n=1$ to $n=6$ and the hydriding rate decreases as the number of cycles increased from $n=6$, indicating that activation is completed at the fifth cycle. At $n=6$, pure $\mathrm{Mg}$ absorbs $1.76 \mathrm{wt} \% \mathrm{H}$ for $5 \mathrm{~min}, 2.17 \mathrm{wt} \% \mathrm{H}$ for $10 \mathrm{~min}, 2.87 \mathrm{wt} \% \mathrm{H}$ for $30 \mathrm{~min}$ and $3.40 \mathrm{wt} \% \mathrm{H}$ for $60 \mathrm{~min}$.

SEM micrographs of pure Mg and pure Mg dehydrided at the tenth hydriding-dehydriding cycle are shown in figure 2. The particles of pure Mg have a few cracks with quite flat surfaces. The pure Mg dehydrided at the tenth

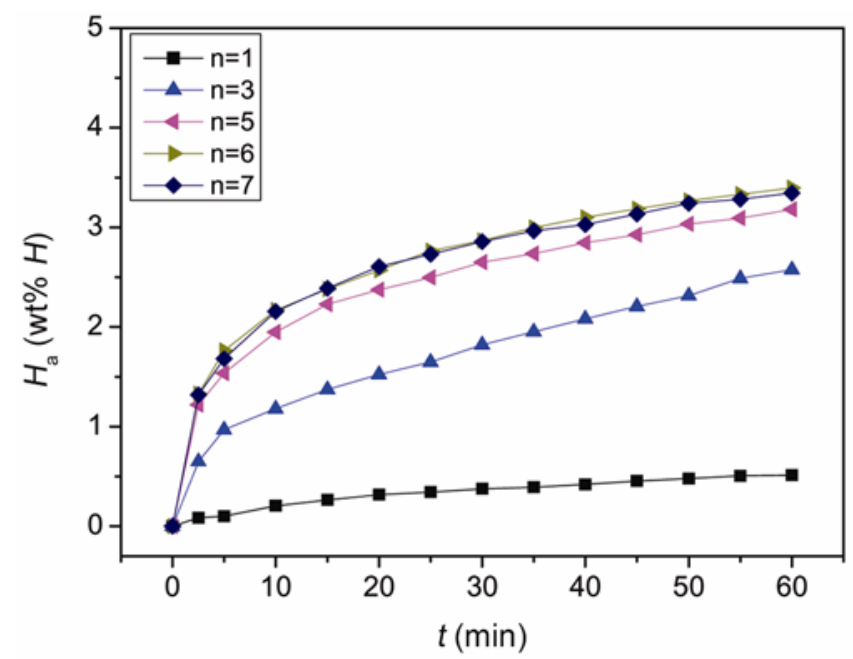

Figure 1. Variation of $H_{\mathrm{a}}$ vs $t$ curve with number of cycles for pure $\mathrm{Mg}$ at $593 \mathrm{~K}$ under 12 bar $\mathrm{H}_{2}$. hydriding-dehydriding cycle, quite small particles coexist with larger particles and particles are smaller than those of the pure $\mathrm{Mg}$ before hydriding-dehydriding cycling, with fine particles on their surfaces. Quite small particles and fine particles are created with hydriding-dehydriding cycling. The expansion and contraction of $\mathrm{Mg}$ with hydriding and dehydriding reactions are believed to be responsible for the formation of these quite small and fine particles.

Figure 3 shows XRD pattern of pure Mg. The sample contains only Mg phase.

The variation of $H_{\mathrm{a}}$ vs $t$ curve with the number of cycles for pure Mg after RMG at $593 \mathrm{~K}$ under 12 bar $\mathrm{H}_{2}$ is shown in figure 4 . At $n=1$, the sample absorbs a very small amount of hydrogen. At $n=1$, pure Mg after RMG absorbs $0.08 \mathrm{wt} \% \mathrm{H}$ for $2.5 \mathrm{~min}$ and $0.14 \mathrm{wt} \% \mathrm{H}$ for $60 \mathrm{~min}$. The hydriding rate of pure $\mathrm{Mg}$ after RMG increases as the number of cycles increases from $n=1$ to $n=7$ and decreases as the number of cycles increases
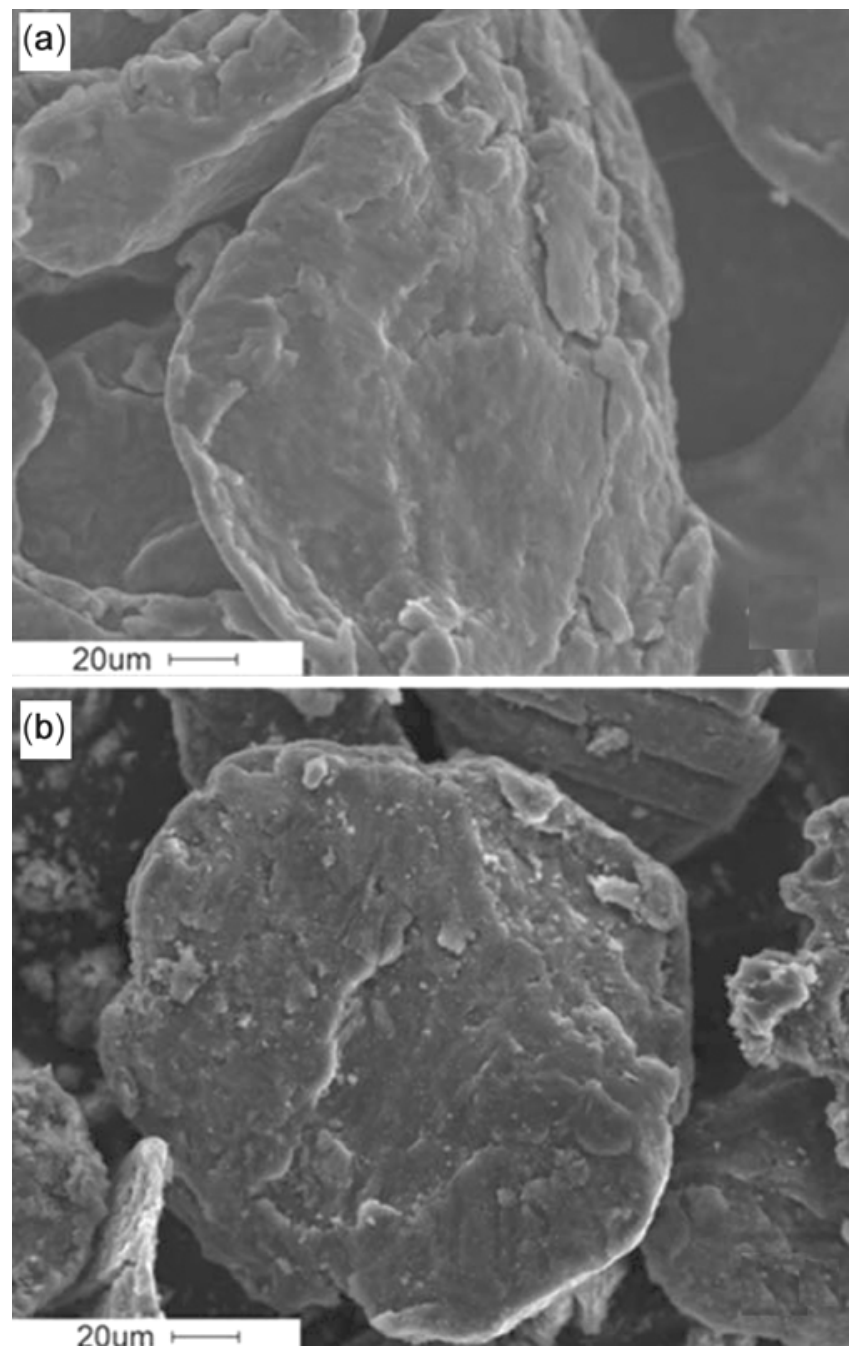

Figure 2. SEM micrographs of (a) pure $\mathrm{Mg}$ and (b) pure $\mathrm{Mg}$ dehydrided at tenth hydriding-dehydriding cycle. 


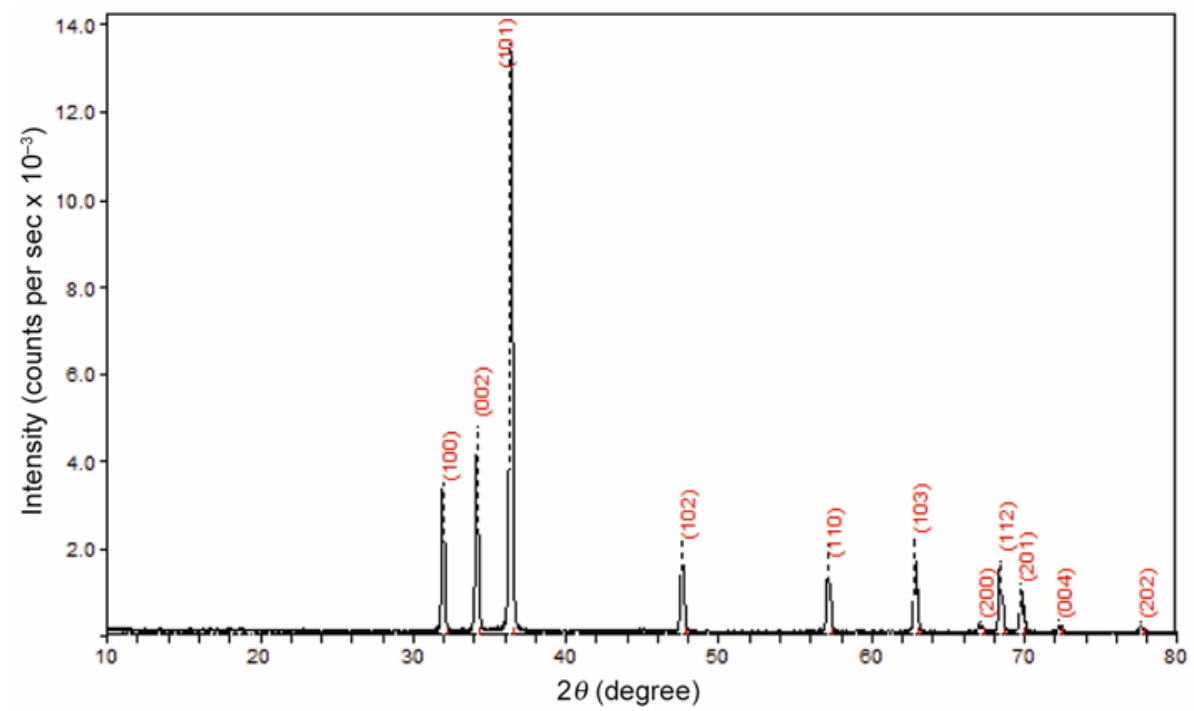

Figure 3. XRD pattern of pure Mg.

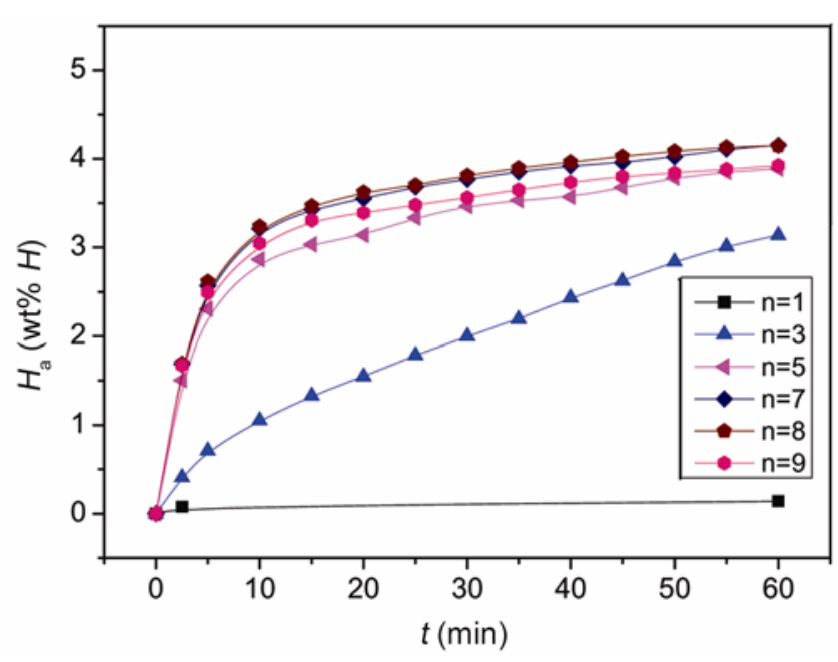

Figure 4. Variation of $H_{\mathrm{a}}$ vs $t$ curve with number of cycles for

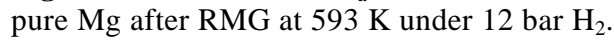

from $n=7$ to $n=8$. At $n=7$, pure Mg after RMG absorbs $2.57 \mathrm{wt} \% \mathrm{H}$ for $5 \mathrm{~min}, 3.21 \mathrm{wt} \% \mathrm{H}$ for $10 \mathrm{~min}, 3.77 \mathrm{wt} \%$ $\mathrm{H}$ for $30 \mathrm{~min}$ and $4 \cdot 15 \mathrm{wt} \% \mathrm{H}$ for $60 \mathrm{~min}$.

Figure 5 shows SEM micrographs of pure Mg after RMG and pure Mg after RMG dehydrided at the twelfth hydriding-dehydriding cycle. After reactive mechanical grinding, ductile $\mathrm{Mg}$ particles formed plastically into elongated and flat shapes via collisions with the steel balls and fine cracks formed by repeated impact forces during ball milling. However, growth rate of microcracks was very slow and fine powder could not be obtained by milling for $6 \mathrm{~h}$. Therefore, pure $\mathrm{Mg}$ after RMG absorbs a very small amount of hydrogen at the first cycle, as shown in figure 4 . In the pure $\mathrm{Mg}$ after RMG dehydrided at the twelfth hydriding-dehydriding cycle, quite small particles coexist with larger particles and particles are much smaller than those of pure $\mathrm{Mg}$ after RMG, with fine particles on their surfaces. Cracks are observed. Cracks, quite small particles and fine particles are created with hydriding-dehydriding cycling. The expansion and contraction of $\mathrm{Mg}$ with hydriding and dehydriding reactions is believed to be responsible for the formation of these cracks, quite small particles and fine particles. Compared with pure Mg dehydrided at the tenth hydriding-dehydriding cycle (figure 2), the particles are smaller or finer and more cracks are observed in pure Mg after RMG dehydrided at the twelfth hydridingdehydriding cycle.

XRD pattern of pure $\mathrm{Mg}$ after reactive mechanical grinding is shown in figure 6. The sample contains $\mathrm{Mg}$ and a very small amount of $\mathrm{MgH}_{2}$, which is formed by the reaction of $\mathrm{Mg}$ with hydrogen during milling under $\mathrm{H}_{2}$.

The variations in the quantity of hydrogen absorbed at $593 \mathrm{~K}$ under 12 bar $\mathrm{H}_{2}$ for $60 \mathrm{~min}, H_{\mathrm{a}}$ (60 min), with the number of cycles for pure $\mathrm{Mg}$ and pure $\mathrm{Mg}$ after RMG are shown in figure 7 . The value of $H_{\mathrm{a}}(60 \mathrm{~min})$ for pure $\mathrm{Mg}$ increases as the number of cycles increases from $n=1$ to $n=6$ and decreases from $n=6$ to $n=7$. The values of $H_{\mathrm{a}}(60 \mathrm{~min})$ for pure $\mathrm{Mg}$ are $0.51,3.40$ and $3.35 \mathrm{wt} \% \mathrm{H}$ at $n=1,6$ and 7, respectively. The value of $H_{\mathrm{a}}$ (60 min) for pure $\mathrm{Mg}$ after RMG increases as the number of cycles increases from $n=1$ to $n=7$ and decreases from $n=7$ to $n=9$. The values of $H_{\mathrm{a}}(60 \mathrm{~min})$ for pure Mg after RMG are $0 \cdot 14,4 \cdot 15$ and $3.93 \mathrm{wt} \% \mathrm{H}$ at $n=1,7$ and 9, respectively. Pure Mg after RMG has smaller $H_{\mathrm{a}}$ (60 min) values than pure $\mathrm{Mg}$ at $n=1$ and $n=2$. After reactive mechanical grinding, the particles of pure $\mathrm{Mg}$ after RMG do not become smaller than those of pure Mg. Ductile Mg particles formed plastically into elongated 

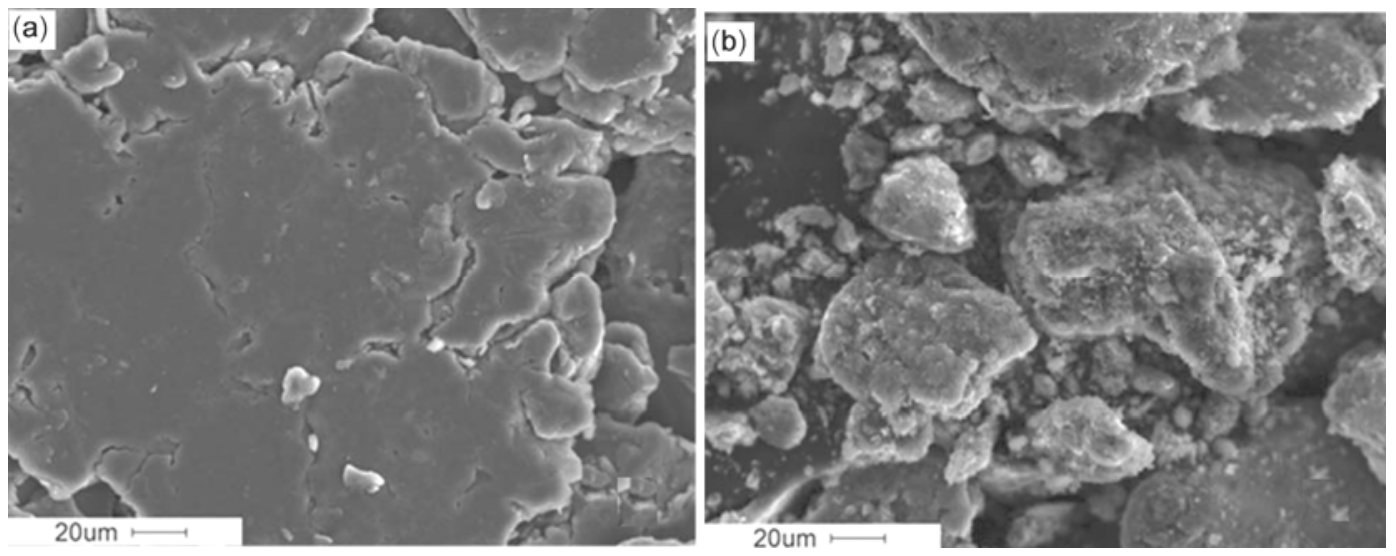

Figure 5. SEM micrographs of (a) pure Mg after RMG and (b) pure Mg after RMG dehydrided at twelfth hydriding-dehydriding cycle.

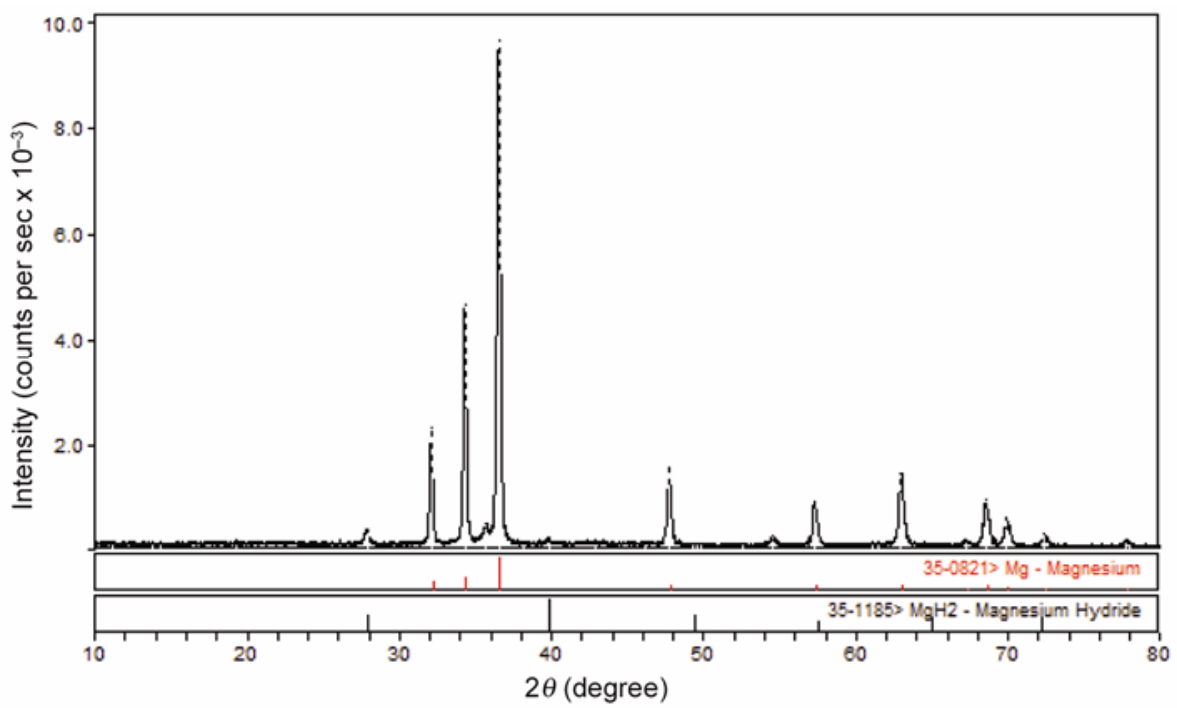

Figure 6. XRD pattern of pure $\mathrm{Mg}$ after reactive mechanical grinding.

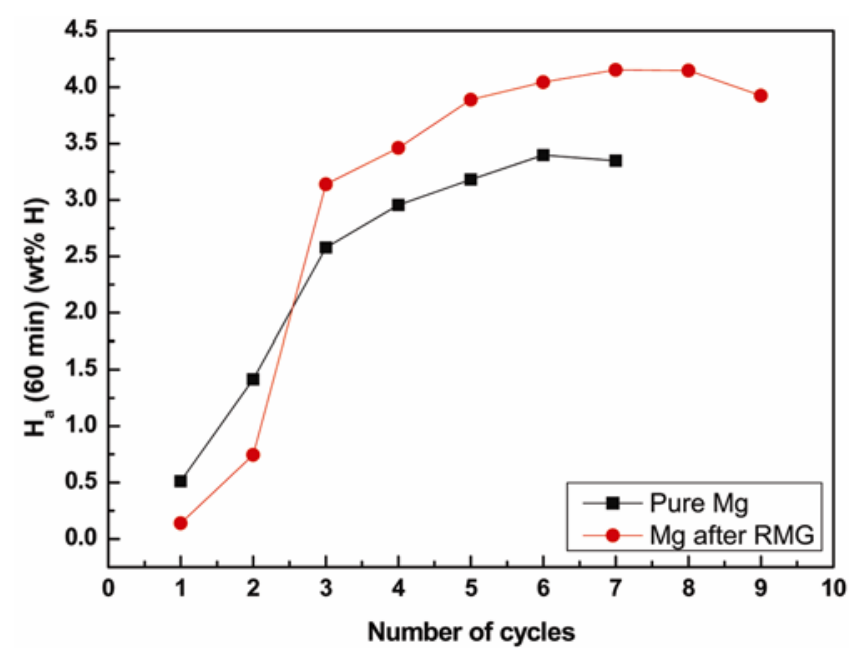

Figure 7. Variations in quantity of hydrogen absorbed at $593 \mathrm{~K}$ under 12 bar $\mathrm{H}_{2}$ for $60 \mathrm{~min}\left(H_{\mathrm{a}}(60 \mathrm{~min})\right)$ with the number of cycles for pure Mg and pure Mg after RMG.

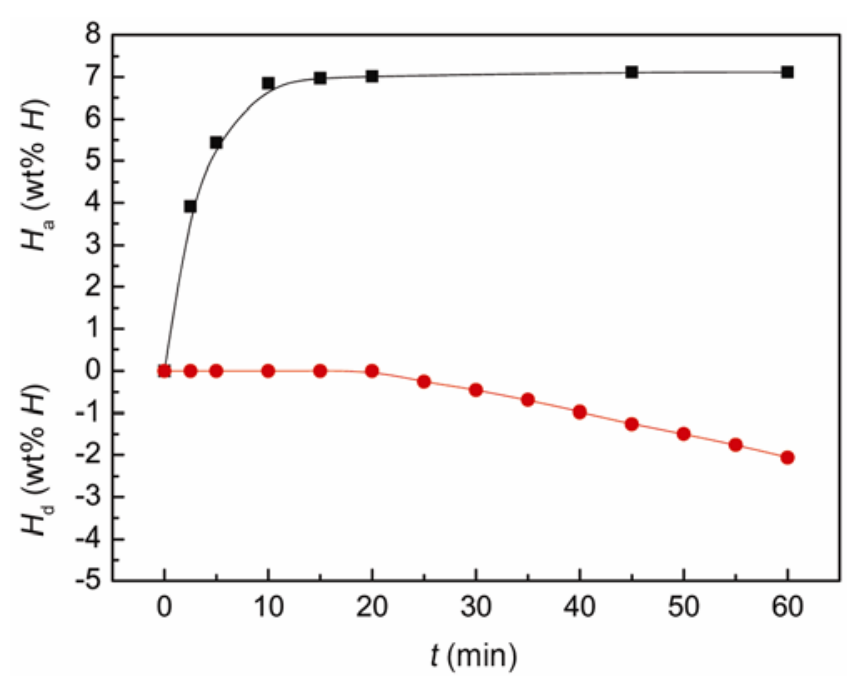

Figure 8. $\quad H_{\mathrm{a}}$ vs $t$ curve under 12 bar $\mathrm{H}_{2}$ and $H_{\mathrm{d}}$ vs $t$ curve under 1 bar $\mathrm{H}_{2}$ at $593 \mathrm{~K}$ at $n=1$ for $\mathrm{MgH}_{2}$ after RMG. 
and flat shapes with a few cracks. This is believed to be responsible for the smaller $H_{\mathrm{a}}$ (60 $\mathrm{min}$ ) values of pure $\mathrm{Mg}$ after RMG than pure Mg at $n=1$ and $n=2$. Pure $\mathrm{Mg}$ after RMG has larger $H_{\mathrm{a}}$ (60 min) values than pure $\mathrm{Mg}$ from $n=3$ to $n=9$. Pure Mg after RMG dehydrided at the twelfth hydriding-dehydriding cycle has smaller particles and a much larger number of defects, with some cracks, than pure Mg dehydrided at the tenth hydridingdehydriding cycle. This is believed to lead to the larger $H_{\mathrm{a}}$ (60 min) values of pure Mg after RMG than pure Mg from $n=3$ to $n=9$.

The reactive mechanical grinding of $\mathrm{Mg}$ and the hydriding-dehydriding cycling of pure Mg after RMG is believed to facilitate nucleation by creating defects on the surface and in the interior of $\mathrm{Mg}$ which can act as active sites for nucleation, and shorten the diffusion distances of hydrogen atoms by forming cracks in $\mathrm{Mg}$ and reducing Mg particle size.

Hydrided pure $\mathrm{Mg}$ and hydrided pure $\mathrm{Mg}$ after RMG did not release hydrogen at $593 \mathrm{~K}$ under 1 bar $\mathrm{H}_{2}$. A pure magnesium sample with smaller particle sizes was prepared by reactive mechanical grinding of $\mathrm{MgH}_{2}$. The weight percentage of desorbed hydrogen, $H_{\mathrm{d}}$, is also expressed with respect to the sample weight. Figure 8 shows $H_{\mathrm{a}}$ vs $t$ curve under 12 bar $\mathrm{H}_{2}$ and the $H_{\mathrm{d}}$ vs $t$ curve under 1 bar $\mathrm{H}_{2}$ at $593 \mathrm{~K}$ at $n=1$ for $\mathrm{MgH}_{2}$ after RMG. $\mathrm{MgH}_{2}$ after RMG has very high hydriding rate. This sample absorbs $5.44 \mathrm{wt} \% \mathrm{H}$ for $5 \mathrm{~min}, 6.85 \mathrm{wt} \% \mathrm{H}$ for $10 \mathrm{~min}$, $7.02 \mathrm{wt} \% \mathrm{H}$ for $20 \mathrm{~min}$ and $7 \cdot 11 \mathrm{wt} \% \mathrm{H}$ for $60 \mathrm{~min}$. This sample shows an incubation period of $20 \mathrm{~min}$ and desorbs $0.26 \mathrm{wt} \% \mathrm{H}$ for $25 \mathrm{~min}, 0.46 \mathrm{wt} \% \mathrm{H}$ for $30 \mathrm{~min}$, $0.98 \mathrm{wt} \% \mathrm{H}$ for $40 \mathrm{~min}$ and $2.07 \mathrm{wt} \% \mathrm{H}$ for $60 \mathrm{~min}$.

\section{Conclusions}

The hydrogen storage properties of pure Mg were studied. To increase the hydriding and dehydriding rate, pure $\mathrm{Mg}$ was ground under hydrogen atmosphere and its hydrogen storage properties were investigated. Pure Mg absorbed hydrogen very slowly. At $n=1$, pure $\mathrm{Mg}$ sample absorbed $0.05 \mathrm{wt} \% \mathrm{H}$ for $5 \mathrm{~min}, 0.08 \mathrm{wt} \% \mathrm{H}$ for $10 \mathrm{~min}$ and $0.29 \mathrm{wt} \% \mathrm{H}$ for $60 \mathrm{~min}$ at $593 \mathrm{~K}$ under 12 bar $\mathrm{H}_{2}$. Activation was completed at the fifth cycle. At $n=6$, pure $\mathrm{Mg}$ absorbed 1.76 wt\% $\mathrm{H}$ for $5 \mathrm{~min}, 2 \cdot 17 \mathrm{wt} \% \mathrm{H}$ for $10 \mathrm{~min}$ and $3.40 \mathrm{wt} \% \mathrm{H}$ for $60 \mathrm{~min}$. The activation of pure $\mathrm{Mg}$ after RMG was completed at the sixth cycle. At $n=7$, pure $\mathrm{Mg}$ after RMG absorbed $2.57 \mathrm{wt} \% \mathrm{H}$ for $5 \mathrm{~min}, 3.21 \mathrm{wt} \% \mathrm{H}$ for $10 \mathrm{~min}$ and $4.15 \mathrm{wt} \% \mathrm{H}$ for
$60 \mathrm{~min}$. The reactive mechanical grinding of $\mathrm{Mg}$ and the hydriding-dehydriding cycling of pure Mg after RMG is believed to facilitate nucleation by creating defects on the surface and in the interior of $\mathrm{Mg}$ which can act as active sites for nucleation, and shorten the diffusion distances of hydrogen atoms by forming cracks in $\mathrm{Mg}$ and reducing the $\mathrm{Mg}$ particle size.

\section{References}

Akiba E, Nomura K, Ono S and Suda S 1982 Int. J. Hydrogen Energy 17787

Aminorroaya S, Ranjbar A, Cho Y H, Liu H K and Dahle A K 2011 Int. J. Hydrogen Energy 36571

Boulet J M and Gerard N 1983 J. Less-Common Met. 89 151

Cho Y H, Aminorroaya S, Liu H K and Dahle A K 2011 Int. J. Hydrogen Energy 364984

Eisenberg F G, Zagnoli D A and Sheridan III J J 1980 J. LessCommon Met. 74323

Hong S H and Song M Y 2013a Met. Mater. Int. 19895

Hong S H and Song M Y 2013b Met. Mater. Int. 191145

Kwak Y J, Park H R and Song M Y 2013 Met. Mater. Int. 19 543

Li Z, Liu X, Huang Z, Jiang L and Wang S 2006 Rare Metals 25247

Li Z, Liu X, Jiang L and Wang S 2007 Int. J. Hydrogen Energy 321869

Lucaci M, Biris A R, Orban R L, Sbarcea G B and Tsakiris V 2009 J. Alloys Compd. 488163

Milanese C, Girella A, Bruni G, Cofrancesco P, Berbenni V, Matteazzi P and Marini A 2010 Intermetallics 18203

Mintz M H, Gavra Z and Hadari Z 1978 J. Inorg. Nucl. Chem. 40765

Pei P, Song X, Liu J, Song A, Zhang P and Chen G 2012 Int. J. Hydrogen Energy 37984

Reilly J J and Wiswall R H 1967 Inorg. Chem. 62220

Reilly J J and Wiswall Jr R H 1968 Inorg. Chem.7 2254

Song M Y, Baek S H, Bobet J-L and Hong S H 2010 Int. J. Hydrogen Energy 3510366

Song M Y, Baek S H, Bobet J-L, Park H R and Kim B G 2013a Met. Mater. Int. 19237

Song M Y, Kwak Y J, Lee S H, Park H R and Kim B G 2013b Met. Mater. Int. 19879

Song M Y, Kwon S N, Mumm D R and Park H R 2013c Met. Mater. Int. 19309

Song M Y, Kwon S N, Park H R and Mumm D R 2013d Met. Mater. Int. 191139

Tanguy B, Soubeyroux J L, Pezat M, Portier J and Hagenmuller P 1976 Mater. Res. Bull. 111441

Zhong H C, Wang H, Ouyang L Z and Zhu M 2011 J. Alloys Compd. $\mathbf{5 0 9} 4268$ 